\title{
Sacral Nerve Stimulation for Faecal Incontinence
}

\author{
Stephen H. Pillinger Angela Gardiner Graeme S. Duthie \\ University of Hull, Academic Surgical Unit, Castle Hill Hospital, Cottingham, UK
}

\section{Key Words}

Incontinence · Sacral nerve stimulation

\begin{abstract}
Faecal incontinence is a common problem. Conservative measures are effective in a significant proportion of patients. Failure of conservative management has until recently meant recourse to surgical intervention. Surgical treatment is often associated with disappointing results. Recently, sacral nerve stimulation (SNS) has been developed as a minimally invasive, effective technique for idiopathic and acquired faecal incontinence. The technique uses chronic low-level electrical stimulation of the sacral nerves, or neuromodulation, to produce a clinically beneficial effect on the distal colon and rectum, the pelvic floor and the anal sphincter complex. SNS is a 2stage procedure: a diagnostic stage - temporary percutaneous nerve evaluation (PNE), and a therapeutic stage permanent SNS. The predictive value of PNE is high, and the surgical trauma and morbidity of both procedures extremely low. The technique has been adapted from its original application in urinary dysfunction. It is almost impossible to produce level 1 evidence for this type of intervention; however, the results are superior to other interventions. Patient selection criteria are evolving, but there is a growing body of evidence that supports its use as first-line treatment for faecal incontinence in patients where conservative measures have failed.
\end{abstract}

Copyright $(2005$ S. Karger AG, Basel

\section{Introduction}

Faecal continence is maintained through complex coordinated activity between the anal sphincters and the rectum. Reflex and voluntary activity of the internal and external sphincters, the puborectalis sling, rectal compliance and sensitivity all make important contributions to continence. Interference with any of these mechanisms can result in incontinence, which in the UK affects $1.4 \%$ of the population over 40 years [1].

Conservative management of faecal incontinence is effective in greater than $50 \%$ of patients. The algorithm of management includes dietary advice, antidiarrhoeal and constipating medication, biofeedback therapy $[2,3]$, and more recently, rectal irrigation [4]. Until recently, surgical intervention was the next step for those patients with persistent severe incontinence.

Surgical treatment for incontinence focuses on the sphincters. With an external sphincter defect, usually due to an obstetric injury, overlap repair can produce reasonable results [5]. Up to $80 \%$ of patients report good symptom control in the short term [6, 7]. However, control deteriorates over time with only $50 \%$ having improved continence at 5 years, with no patient maintaining full continence [8].

Other surgical options are dynamic graciloplasty, artificial bowel sphincter implants and the antegrade continent enema. These are major operations with high morbidity and failure rates $[9,10]$. The final option is a permanent stoma.

\begin{tabular}{ll}
\hline KARGER & ( ) 2005 S. Karger AG, Basel \\
0253-4886/05/0221-0001\$22.00/0 \\
$\begin{array}{l}\text { Fax +4161306 12 34 } \\
\begin{array}{l}\text { E-Mail karger@karger.ch } \\
\text { www.karger.com }\end{array}\end{array}$ & $\begin{array}{l}\text { Accessible online at: } \\
\text { www.karger.com/dsu }\end{array}$
\end{tabular}

G.S. Duthie, MD

The University of Hull, Academic Surgical Unit, Castle Hill Hospital Castle Road

Cottingham, East Yorkshire, HU16 5JQ (UK)

Tel. +44 1482623 247, Fax +44 1482623 274, E-Mail g.s.duthie@medschool.hull.ac.uk 
A functional deficit without a definable sphincter defect represents a significant therapeutic dilemma. Surgical correction in this situation has again led to a transient improvement in around $50 \%$ of patients [11]. These disappointing results are not surprising as it is an attempt to apply a mechanical solution to a dynamic problem. The finding that direct electrical stimulation of the peripheral nerve supply of the striated pelvic floor, urinary and anal sphincter muscles improves their function led to the use of sacral nerve stimulation (SNS) in faecal incontinence [12].

\section{Evolution of the Procedure}

Direct neural stimulation to produce a clinical effect was first hypothesized as long ago as 1906 [13]. Experimental work using SNS for functional disturbances of micturition began in the 1950s, with stimulation of the spinal cord, the detrusor muscle and the striated sphincter used to try and provoke controlled micturition [14-17]. The first clinical application of these principles was an SNS implant performed in 1981 by Tanagho and Schmidt [18]. In 1990, Brindley [19] reported his technique for anterior sacral nerve root stimulation in patients with urinary dysfunction secondary to chronic spinal injury. With these insensate patients, short-lived high-voltage stimulation could be employed to produce tetanic contraction of bladder and sphincter. Once the stimulus was removed, the 'fast twitch' sphincter muscle relaxed quickly and the 'slow twitch' detrusor relaxed slowly, thereby creating a pressure differential to facilitate micturition. Bowel function was also affected in these patients, with the induction of peristaltic, frequency-dependant, high-pressure colorectal contractions.

The Brindley technique causes pain in patients with an intact spinal cord. Therefore, chronic stimulation at low amplitude, or neuromodulation, was employed for urological dysfunction in these patients. This evolved to the current indication: SNS to control voiding difficulties and urinary incontinence when the urinary tract seems to be structurally intact, but functionally deficient $[20,21]$.

A small case series in 1995 reported the results of SNS in 3 patients [12] with faecal incontinence. Two recovered complete continence and the third had some soiling. The authors attributed the results to an increase in anal canal closing pressure, and possibly to a 'permanent training effect' on the external sphincter with transformation of fast twitch, fatiguable muscle fibres to slow twitch, fatigue-resistant fibres. However, it has since been shown that patients implanted with a permanent SNS have only a modest improvement in external anal sphincter function [22]. Secondly, the delay from spinal nerve stimulation to pelvic floor response is 10 times greater than would be expected through a direct efferent pathway [23], suggesting a more complex mode of action.

\section{Methods}

\section{Patient Selection}

The aetiology of incontinence in the larger series includes obstetric injury, idiopathic scleroderma, incontinence persisting after repair of complete external rectal prolapse, spinal trauma and following anal surgery. All patients, regardless of the aetiology of their incontinence, are thoroughly assessed prior to SNS. In the UK, the NHS National Institute for Clinical Excellence guidelines suggest the technique is performed under the auspices of a research trial and only in centres with facilities for full anorectal investigation. The patients have failed medical therapy and other non-invasive treatments such as biofeedback, and have an intact sphincter mechanism. A previous sphincter repair is not a contraindication.

Patients are assessed clinically, then complete a bowel diary for a 2- or 3-week period and a Short Form 36 Health Survey quality of life questionnaire [24]. The Cleveland Clinic Incontinence Score questionnaire [25] has been completed by the latest group of patients. Endoanal ultrasound and anorectal physiology testing are then performed on each patient. This assessment includes anal manometry, rectal capacity and sensitivity testing with balloon distension, and pudendal nerve terminal motor latency measurement. The bowel diary is kept during the temporary percutaneous nerve evaluation (PNE) period, and some centres repeat the physiology testing during this period.

Patient selection for permanent implantation is based on patient satisfaction and the degree of improvement in continence as determined from the bowel diaries and questionnaires. A permanent implant would not usually be considered without a $50 \%$ or greater improvement in the number of faecal incontinence episodes or the number of days affected by incontinence.

\section{Percutaneous Nerve Evaluation}

SNS is a two-stage procedure: PNE - the 'trial-run' diagnostic stage, and the permanent implant - the therapeutic stage. The technique for implantation of both temporary and permanent SNS devices has been described previously [26], and it is not surprising that it is fairly standardized. Modifications have been made by different centres, particularly with the equipment. Early in the UK experience [27], test stimulation employed a percutaneous wire electrode (Medtronic 004; Medtronic Interstim, Minneapolis, Minn., USA) that attached to a portable stimulator (Medtronic 3625). This smooth wire was easily dislodged. This problem was addressed by implanting a fixed electrode (Medtronic 3080) connected to the external stimulator using an extension cable. This extension cable was then removed prior to connecting the implanted pulse generator (Medtronic 3023) to the fixed electrode. This system with percutaneous connection to the fixed electrode had potential for infection, and indeed, a number of implants were removed due to infection (the precise number is unreported). A helical wire electrode (Medtronic 
3057) with a rough surface less prone to dislodgement was then developed to allow true 'percutaneous' temporary testing.

The patient is positioned identically for PNE and permanent implant in the prone jack-knife position. The sacral foramina are identified using bony landmarks [28], and a 20-gauge spinal needle is inserted into the $\mathrm{S}_{2}, \mathrm{~S}_{3}$ and $\mathrm{S}_{4}$ foramina bilaterally. A portable stimulator (Medtronic 3625) is used in sequence to elicit the best response to the lowest stimulus. The best response is a 'bellows'-type contraction of the perineum accompanied by plantar flexion of the ipsilateral great toe. Once the best foramen is identified, the temporary electrode is passed through the needle, the needle removed and the electrode fixed to the skin.

PNE can be performed under local or general anaesthesia. Our own preference is to perform the procedure under general anaesthesia without paralysis, as there is then no interference with assessing the response to stimulus; it is more comfortable for the patient and the test can be carried out meticulously. Most centres use a single dose of prophylactic intravenous antibiotic. Anterior-posterior and lateral pelvic X-rays are taken the following day, prior to stimulation. The test period is $1-3$ weeks and is assessed as outlined above. The temporary electrode is removed at the end of the test period, in our case, by our clinical physiologist in the physiology laboratory. There is a certain elegance in the procedure, as there is the unique advantage of being able to test each patient with temporary PNE prior to a permanent implant. The patient is also aware of the 'level of success' he/she can expect.

\section{Permanent Implantation}

The patient is positioned as for the PNE procedure. Antibiotic prophylaxis is used again, and all equipment to be implanted is soaked in gentamicin. The nerve root of best response is again identified. This is almost always the root used for the PNE. The majority of permanent implants have been performed using an open technique, where the sacral foramina are identified through a small midline incision and the stimulation electrode is secured to the periosteum. However, the authors favour a percutaneous Seldinger-type technique, utilizing a tyned lead (Medtronic 3093). The position of the tyned lead is checked with an image intensifier before the tynes are deployed. A hard-copy film of the final position is taken in theatre. A small incision is still required in the ipsilateral buttock to position the permanent impulse generator (Medtronic 3023). An extension cable (Medtronic 3010) is tunnelled subcutaneously to connect the tyned lead and the impulse generator.

The next day, external telemetry is used to switch on the impulse generator. The stimulation parameters are readily modified with telemetry and are set with the patient fully awake and responsive. The parameters are usually the same as the PNE levels. In our unit, the frequency is set at $14 \mathrm{~Hz}$ and the pulse width is $210 \mathrm{~ms}$. Amplitude is the only real variable in most centres, and we follow the convention of setting it to the level of initial patient sensation.

\section{Results}

The most striking aspect of the results reported is that all patients who benefit from temporary stimulation appear to have a predictable benefit from a permanent implant. The availability of a relatively simple screening procedure with $100 \%$ positive predictive value has staggering implications for the treatment of patients. Given the low morbidity of PNE, it is almost the perfect screening tool.

There is a failure rate in PNE of 12-22\% [27, 29], and those patients who have not responded to a permanent implant are those who had no response to screening [27, 30]. Failure to respond may be due to a number of factors such as lead displacement, genuine absence of response or neurological injury. SNS is not effective in patients with a high complete spinal cord transection [31]. Indeed, neurological integrity would seem to be a pre-requisite as the technique has not been used successfully in patients with complete pudendal nerve lesions [28, 31]. A prolonged pudendal nerve terminal motor latency does not appear to preclude a symptomatic improvement.

A recent review of SNS for the treatment of faecal incontinence [32] summarized the excellent clinical results of SNS to this point. All series [12, 27, 29, 31, 33-37] have reported a reduction in episodes of faecal incontinence to a median of $6 \%$ or less, with the larger series reporting rates less than $2 \%$. There are no long-term results as yet; however, the benefits appear to be maintained in the medium term [37], with the longest followup being 7 years [27]. Improvements in quality of life scores appear to reflect the improvement in continence scores $[27,37]$.

It is difficult with this type of intervention to produce level 1 prospective randomized controlled trial data, as blinding the patient and the reviewer is all but impossible. There has been one small but elegant study performed to try and control for placebo effect [38]. Although only involving 2 patients, this was a double-blind crossover study. Both patients had been implanted with a permanent SNS for 9 months. The trial period consisted of two 2 -week periods, with the stimulator turned on for 2 weeks and off for 2 weeks. The patients' continence was maintained with stimulation below the sensory threshold; therefore, the patients could not tell if the stimulator was on or off. This trial indicated that the clinical benefit from the SNS was unlikely to be due to a placebo effect.

\section{Complications}

PNE has a morbidity rate of less than $1 \%$, ideal for a screening test. The complication rate in permanent implantation is difficult to assess, as the complications reported from earlier series, such as wound dehiscence, pain over the extension leads and infection associated 
with a percutaneous extension during PNE, are no longer relevant due to changes in technique. There are $3 \mathrm{im}-$ plants that have been removed due to infection and 2 due to chronic pain $[29,35]$. There have been 4 lead displacements requiring repositioning $[37,29,36]$. We have had 1 displacement using the percutaneous technique with the tyned lead. Lead displacement rates certainly appear no greater with the percutaneous technique [27].

\section{Discussion}

SNS is a relatively straightforward procedure. Electrodes are placed against the nerve roots of the sacral plexus to alter the physiological function of the lower urinary tract, distal colorectum and pelvic floor. The precise mechanism of action remains unknown; however, it is likely that the electrodes cause 'neuromodulation' of multiple nerves within the sacral plexus, including the voluntary somatic, afferent sensory and efferent autonomic motor nerves. The significance of the effect on each type of nerve and whether there is a central effect or not is also uncertain. By utilizing the existing anatomy and stimulating physiological function, it may well be that we at last have a treatment that provides a dynamic solution to a dynamic problem.

Therefore, it is possible to make general recommendations for SNS, but not possible to list hard and fast indica- tions and contraindications. Patients with an intact sphincter and rectum, an intact sacral nerve plexus with an ellicitable pudendal nerve terminal motor latency and no spinal cord lesion would appear to have a favourable prognosis. The absence of any of the above factors is associated with a poorer prognosis. However, the technique continues to evolve. In our unit, we now have 17 patients with sphincter defects who have had permanent implants. The success rate in these patients is $88 \%$ (unpublished data). At the behest of our Pain Service, we have also implanted several patients with chronic pelvic pain with encouraging results. Good results with small numbers of patients have been reported in 2 studies [39, 40] on the use of SNS in constipation.

SNS represents a considerable advance in the treatment of severe persistent faecal incontinence that is unresponsive to conservative treatment. Whilst there are no randomized controlled trials directly comparing SNS with other treatments in the literature, the data supporting its use are becoming more compelling. With durable success rates of up to $80 \%$, it would appear superior to any other treatment for this debilitating and demoralizing condition. It may well become the treatment of choice in patients with faecal incontinence that have failed conservative management. Inevitably, as our understanding of the mechanism of action improves, the indications for SNS will broaden.

\section{References}

$\checkmark 1$ Perry S, Shaw C, McGrother C, Matthews RJ, Assassa RP, Dallosso H, et al: Prevalence of faecal incontinence in adults aged 40 years or more living in the community. Gut 2002;50: 480-484.

2 Norton C, Hosker G, Brazzelli M: Biofeedback and/or sphincter exercises for the treatment of faecal incontinence in adults. Cochrane Database Syst Rev 2000; CD002111.

$\checkmark 3$ Cheetham MA, Kenefick NJ, Kamm MA: Non-surgical treatment of faecal incontinence. Hosp Med 2001;62:538-541.

4 Krogh K, Kvitzau B, Jorgensen TM, Laurberg $\mathrm{S}$ : Treatment of anal incontinence and constipation with transanal irrigation. Ugeskr Laeger 1999; 161:253-256.

$\checkmark 5$ Lehur PA, Michot F, Denis P, et al: Results of artificial sphincter in severe anal incontinence: Report of 14 consecutive implantations. Dis Colon Rectum 1996;39:1352-1355.

6 Engel AF, Kamm MA, Sultan AH, Bartram CI, Nicholls RJ: Anterior anal sphincter repair in patients with obstetric trauma. Br J Surg 1994; 81:1231-1234.
7 Barisic G, Krivokapic Z, Markovic V, et al: The role of overlapping sphincteroplasty in traumatic faecal incontinence. Acta Chir Iugosl 2000;47:37-41.

$>8$ Malouf AJ, Norton CS, Engel AF, Nicholls RJ, Kamm MA: Long-term results of overlapping anterior anal sphincter repair for obstetric trauma. Lancet 2000;355:260-265.

$\checkmark 9$ Baeten CG, Bailey HR, Bakka A, Belliveau P, Berg E, Buie WD, et al: Safety and efficacy of dynamic graciloplasty for fecal incontinence: Report of a prospective, multicenter trial. Dynamic Graciloplasty Therapy Study Group. Dis Colon Rectum 2000;43:743-751.

10 Lehur PA, Glemain P, Bruley des Varannes S, Buzelin JM, Leborgne J: Outcome of patients with an implanted artificial anal sphincter for severe faecal incontinence. A single institution report. Int J Colorectal Dis 1998;13:88-92.

$>11$ Orrom WJ, Miller R, Cornes H, Duthie G, Mortensen NJ, Bartolo DC: Comparison of anterior sphincteroplasty and postanal repair in the treatment of idiopathic fecal incontinence. Dis Colon Rectum 1991;34:305-310.
12 Matzel KE, Stadelmaier U, Hohenfellner M, Gall FP: Electrical stimulation of sacral spinal nerves for treatment of faecal incontinence. Lancet 1995;346:1124-1127.

13 von Frankl-Hochwart L, Zuckerkandl O: Die nervösen Erkrankungen der Harnblase; in Nothnagel H (ed): Spezielle Pathologie und Therapie. Wien, A. Holder, 1906, p 109.

14 Bradley WE, Timm GW, Chou SN: A decade of experience with electronic stimulation of the micturition reflex. Urol Int 1971;26:283-302.

$>15$ Held T, Agrawal G, Kantrowitz A: Studies in stimulation of the bladder and its motor nerves. Surgery 1966;60:848-856.

16 Ingersoll EH, Jones LL, Hegre ES: Effect on urinary bladder of unilateral stimulation of pelvic nerves in the dog. Am J Physiol 1957;189: 167-171.

17 Holmquist B: Electromicturition by pelvic nerve stimulation in dogs. Scand J Urol Nephrol 1968;(suppl 2):1-27.

18 Tanagho EA, Schmidt RA: Bladder pacemaker: Scientific basis and clinical future. Urology 1982;20:614-619. 
19 Brindley GS: Treatment of urinary and faecal incontinence by surgically implanted devices. Ciba Found Symp 1990;151:267-274.

20 Bazeed MA, Thuroff JW, Schmidt RA, Wiggin DM, Tanagho EA: Effect of chronic electrostimulation of the sacral roots on the striated urethral sphincter. J Urol 1982;128:13571362 .

21 Tanagho EA, Schmidt RA: Electrical stimulation in the chronic management of the neurogenic bladder. J Urol 1988;140:1331-1339.

-22 Kenefick NJ, Emmanuel A, Nicholls RJ, Kamm MA: Effect of sacral nerve stimulation on autonomic nerve function. Br J Surg 2003; 90:1256-1260.

-23 Fowler CJ, Swinn MJ, Goodwin RJ, Oliver S, Craggs M: Studies of the latency of pelvic floor contraction during peripheral nerve evaluation show that muscle response is reflexly mediated. J Urol 2000; 163:881-883.

24 Jenkinson C, Coulter A, Wright L: Short form 36 (SF36) health survey questionnaire: Normative data for adults of working age. BMJ 1993; 306:1437-1440.

$\checkmark 25$ Jorge JM, Wexner SD: Etiology and management of fecal incontinence. Dis Colon Rectum 1993;36:77-97.

-26 Bosch JL, Groen J: Sacral (S3) segmental nerve stimulation as a treatment for urge incontinence in patients with detrusor instability: Results of chronic electrical stimulation using an implantable neural prosthesis. J Urol 1995; 154:504-507.
27 Jarrett M, Varma J, Duthie G, Nicholls RJ, Kamm MA: Sacral nerve stimulation for faecal incontinence: The UK experience. Colorectal Dis 2003;5:2.

28 Ganio E, Luc AR, Clerico G, Trompetto M: Sacral nerve stimulation for treatment of fecal incontinence: A novel approach for intractable fecal incontinence. Dis Colon Rectum 2001;44: 619-631.

29 Rosen HR, Urbarz C, Holzer B: Sacral nerve stimulation as a treatment for faecal incontinence. Gastroenterology 2001;121:536-541.

30 Ganio E, Ratto C, Masin A, Luc AR, Doglietto $\mathrm{GB}$, et al: Neuromodulation for fecal incontinence: Outcome in 16 patients with definitive implant. The initial Italian Sacral Neurostimulation Group (GINS) experience. Dis Colon Rectum 2001;44:965-970.

31 Ganio E, Masin A, Ratto C, Altomare DF, Ripetti V, Clerico G, et al: Short-term sacral nerve stimulation for functional anorectal and urinary disturbances: Results in 40 patients: Evaluation of a new option for anorectal functional disorders. Dis Colon Rectum 2001;44: 1261-1267.

32 Kenefick NJ, Christiansen J: A review of sacral nerve stimulation for the treatment of faecal incontinence. Colorectal Dis 2004;6:75-80.

33 Vaizey CJ, Kamm MA, Turner IC, Nicholls RJ, Woloszko J: Effects of short-term sacral nerve stimulation on anal and rectal function in patients with anal incontinence. Gut 1999; 44:407-412.
34 Malouf AJ, Vaizey CJ, Nicholls RJ, Kamm MA: Permanent sacral nerve stimulation for fecal incontinence. Ann Surg 2000;232:143148.

35 Matzel KE, Stadelmaier U, Hohenfellner M, Hohenberger W: Chronic sacral spinal nerve stimulation for faecal incontinence: Long-term results with foramen and cuff electrodes. Dis Colon Rectum 2001;44:59-66.

36 Leroi AM, Michot F, Grise P, Denis P: Effect of sacral nerve stimulation in patients with faecal and urinary incontinence. Dis Colon Rectum 2001;44:779-789.

37 Kenefick NJ, Vaizey CJ, Cohen RG, Nicholls RJ, Kamm MA: Medium-term results of sacral nerve stimulation for faecal incontinence. $\mathrm{Br} \mathrm{J}$ Surg 2002;89:896-901.

38 Vaizey CJ, Kamm MA, Roy AJ, Nicholls RJ: Double-blind crossover study of sacral nerve stimulation for fecal incontinence. Dis Colon Rectum 2000;43:298-302.

39 Kenefick NJ, Nicholls RJ, Cohen RG, Kamm MA: Permanent sacral nerve stimulation for treatment of idiopathic constipation. Br J Surg 2002;89:882-888.

40 Malouf AJ, Wiesel PH, Nicholls T, Nicholls RJ, Kamm MA: Short-term effects of sacral nerve stimulation for idiopathic slow transit constipation. World J Surg 2002;26:166-170. 